\title{
The Determinants of the Confidi Delinquency Rate
}

\author{
Alessio Bongiovanni ${ }^{1} \&$ Cristina Rovera ${ }^{1}$ \\ ${ }^{1}$ Business Economics of the Management Department, University of Turin, Italy \\ ${ }^{2}$ Management Department, University of Turin, Italy \\ Correspondence: Cristina Rovera, Management Department, University of Turin, Italy. E-mail: \\ cristina.rovera@unito.it \\ Received: January 17, 2018 \\ Accepted: February 21, 2018 \\ Online Published: March 18, 2018 \\ doi:10.5539/ijbm.v13n4p87 \\ URL: https://doi.org/10.5539/ijbm.v13n4p87
}

\begin{abstract}
This study is focused on the Italian confidi, the financial institutions placed in an intermediate position between lenders and borrowers, because they offer guarantees care of banks to the associated SMEs. During the last years some of the most important guarantee institutions failed, because of bad and doubtful credits. The main aim of the research is to determine the responsible factors about their delinquency rate. The analysis is realized on 99 confidi during 2006-2015 (10 years). The data about 2016 are not usable, because the Italian confidi are living a change in the accountings standards, making it impossible a comparison between the balance sheets. The regression model show that the difficulties in credit collections essentially depend to the economic crisis and to the bad management of the organizations. We cannot also forget the practical and social implications of the study. The forecasting of the riskier confidi will help the Italian policy makers both in the individuation of correct instruments of rescue and in finding a solution for another important problem: the unemployment.
\end{abstract}

Keywords: balance sheet, delinquency rate, mutual guarantee institution, SME

\section{Introduction: The Research Hypothesis}

In order to limit the considerable frictions which characterise the relations between banks and enterprises, banks usually ask for guarantees to hedge a part of potential losses on loans, the aim being to increase the sense of responsibility in the borrowers by reducing the moral hazard typical of lending transactions. While guarantees are particularly important in order to gain access to credit, firms often find it hard to supply financial instruments or assets to cover the loan requested. For this reason, SMEs often apply to mutualistic guarantee institutions, known as "confidi", whose core business is the provision of guarantees to the associated enterprises. Confidi are financial institutions who take an intermediate stance between banks and potential borrowers, in order to support worthy SMEs to access to debt capital that, otherwise, would be denied or would be subject to higher charges. The Italian SMEs represent more of the $95 \%$ of the national companies and the $26 \%$ of them is associated to a guarantee institution. Two different kinds of guarantee organizations are currently present on the market, depending on whether these are or not subject to the supervision by the Bank of Italy. The former must be enrolled in a specific register and must comply with particularly stringent requirements, following rules that are very similar to those of the banks, while the latter are subject to less strict regulation. Both categories present a common feature represented by their strong relationship with their local community and the industrial associations, allowing them to benefit, albeit at different levels, from an extensive set of qualitative information, hardly available to banks.

During 2015 the volume of guarantees of our sample was 5 billions of euro. While from 2006 to 2010 their Compound Annual Growth Rate (CAGR, which measures the period change on an annual basis) was $+13.09 \%$, the last years were characterized by an opposite trend: $-10.74 \%$ from 2010 to 2015 , pointing out a relevant reduction in the provided guarantees. The phenomenon led to the following research question: what factors are responsible about the confidi delinquency rate? The happening can be a consequence of the decrease of the working confidi (more than 200 less since 2011 Note 1), which depends on merger and acquisitions, but also on failures for bad and doubtful credits and on the explosion of the economic and financial crisis. The causes we are looking for are therefore explained by micro (aspects linked to the specific characteristics of the individual confidi) and macro magnitudes (aspects related to the economic sphere of reference). To test the hypothesis we offer both a qualitative and a quantitative analysis. 


\section{Literature}

Previous empirical studies on mutualistic guarantee institutions focused primarily on microeconomic aspects, relating mainly to the risk of the associated enterprises. In this sense, numerous studies seem to confirm how these intermediaries can act as "indicators", certifying the creditworthiness of the firms. Columba et al (2009), confirming the theory that confidi play a crucial role in improving banks' ability to assess and monitor SMEs benefiting from credit, as proven by the probability of default of the firms associated to mutualistic guarantees institutions, which is much lower than that of firms that are not associated. The evidence described above emerges also when we take into consideration the cost of the debt applied to the enterprises which are members of a confidi (Columba et al., 2010). The intervention by confidi can, therefore, be extremely important for the banks which have agreements with them. They can gain a real benefit from the confidi's guarantee, not only because it will cover part of the potential losses, but especially because, by granting the guarantee, it is as though the confidi is implicitly indicating the creditworthiness of the beneficiary enterprise, owing to less risky firms to show this features to the lenders (Busetta \& Zazzaro, 2012).

If we look at the benefits for the affiliated enterprises, the contribution of confidi is particularly important, in that it is capable of alleviating the difficulty in gaining credit, which is considerable for SMEs, (Mistrulli \& Vacca, 2011), as these intermediaries are able to provide a series of soft information, gained by fully exploiting the typical peer monitoring mechanism of mutual institutions (Stiglitz, 1990), the importance of which is accentuated particularly during recessions, in which the bank rating systems, being based on a series of pro-cyclic information, could be less reliable (Bartoli et al., 2010).

Focusing on the possibility that specific characteristics of the single confidi can provide indications regarding the quality of the guarantees portfolio, only a small number of studies has partially analysed this aspect. Gai et al (2013), analysing a panel of loans granted to SMEs, highlighted a greater risk for transactions guaranteed by the deposit of funds held by the beneficiary bank, compared to those benefiting from confidi's equity guarantees. This could also suggest a significant difference regarding the different riskiness of guarantee portfolios between superviseds and non-superviseds.

As the former tend to operate mainly through equity guarantees, unlike those that are not supervised, which use more guarantees based on restricted funds (Isaia et al., 2015); the information obtained in the study could suggest the existence of significant differences between the two categories of confidi linked to the different business model which characterise them. In addition, an increment in the level of leverage of the confidi and in the dimension of the portfolio of the counter-guarantor to which the confidi transfers part of its credit risk show a positive impact on the risk of the loan guaranteed operations (Gai et al., 2016).

To the best of our knowledge, no previous study has focused on the analysis of the confidi delinquency rate. Our work, which examines both the particular aspects of the single confidi and variables relating to the macroeconomic context, proposes to analyse the determinants of the delinquency rate of these institutions, to gain a clearer picture of the desirable features of mutualistic guarantee institutions in order to limit the risk to which they are exposed.

The article is organised into the following sections: section 3, dedicated to describing the method implemented, going into detail in relation to the sample and the data used; section 4, portraying the delinquency rate trend; sections 5, 6 and 7, analyse the results of the regressions, separating those for the entire sample from those relating to supervised confidi only; and, lastly, section 8 , completing the work with a summary of the results.

\section{Method}

\subsection{The Sample}

The complete list of confidi was downloaded from the Bank of Italy website, and - in September 2016 - it included 480 credit guarantee institutions. The first check was on their operationality. Using Telemaco (the database of Italy's Chambers of Commerce), we downloaded their balance sheets for 2006 - 2015 (Note 2):

- 108 confidi were closed or in liquidation;

- 12 did not offer guarantees, but consulting for the partner enterprises;

- 93 had not shown their financial statements for the last one or two financial years.

The need to create a standardised and complete database led us to exclude these categories. Further cleaning of the sample led to the elimination of the associations which did not indicate the delinquencies in at least five of the reference years. The analysis is, therefore, carried out on 99 confidi. They are nevertheless a representative panel, because they disburse $62 \%$ of the Italian system's guarantees. Table 1 offers the details of their geographic origin, operational sector and regulatory discipline. 
Table 1. Geographic area, sector and discipline of the guarantee institutions

\begin{tabular}{lcc}
\hline Geographic area & Number of confidi & $\mathbf{\%}$ \\
\hline North & 53 & $53.54 \%$ \\
of which: & & \\
Northwest & 32 & $32.32 \%$ \\
Northeast & 21 & $21.21 \%$ \\
Centre & 24 & $24.24 \%$ \\
South and Islands & 22 & $22.22 \%$ \\
Total & $\mathbf{9 9}$ & $\mathbf{1 0 0 . 0 0 \%}$ \\
\hline Sector & Number of confidi & $\mathbf{\%}$ \\
\hline Agriculture and fishing (AGR) & 4 & $4.04 \%$ \\
Craftsmanship (CRF) & 21 & $21.21 \%$ \\
Trade, tourism and services (TTS) & 19 & $19.19 \%$ \\
Industry (IND) & 3 & $3.03 \%$ \\
Multisector (MS) & 52 & $52.53 \%$ \\
Total & $\mathbf{9 9}$ & $\mathbf{1 0 0 . 0 0 \%}$ \\
\hline Discipline & 33 & $33.33 \%$ \\
\hline Monitored institutions (art. 106 TUB) & 66 & $66.67 \%$ \\
Unmonitored institutions (art. 112 TUB) & $\mathbf{9 9}$ & $\mathbf{1 0 0 . 0 0 \%}$ \\
Total & & \\
\hline
\end{tabular}

As you can see, the highest percentage of subjects is in the north (54\%), divided into northwest $(32 \%)$ and northeast $(21 \%)$, where Lombardy (18\%) and Veneto (12\%) prevail. There are numerous consortia in the South and Islands (about 38\%) but, unfortunately, they are less diligent. Their elimination from the sample is due to the lack of information provided by their financial statements, which often neglect to indicate the delinquencies accumulated.

The sector derives from the articles of association and the nature of the associated SMEs: the MS prevails (53\%), followed by CRF (21\%), TTS (19\%), AGR (4\%) and IND (3\%).

The last section of the table separates the confidi depending on their size and on the control of Bank of Italy. In compliance with the provisions of the Italian Banking Law (Testo Unico Bancario - TUB) you can distinguish:

- Confidi 106, if their financial assets amount to at least 150 million euros;

- Confidi 112, if they are smaller.

The numbering is due to the regulating article of the TUB. 106 consortia are bigger and therefore subject to special control by the Bank of Italy (monitored confidi). 112 are smaller associations and they are not controlled by Bank of Italy (not monitored confidi), but by a special Organism, created by the Decree-Law n. 141/2010. The difference between the two categories is related not so much to the operations (both offer guarantees), as to their value. The coverage of monitored confidi reduces the risk of the lending bank, in compliance with prudential monitoring provisions. Membership of the group implicates a potential competitive advantage but imposes objective criteria and controlling restrictions which would not otherwise exist. The price to pay is high and has sometimes quashed the desire to be part of the 106 group.

\subsection{The Data}

The analysis was carried out in consideration of micro magnitudes (balance sheet figures) and macro magnitudes (system variables).

Among the asset items, we selected the total assets, in order to evaluate the dimensions of the confidi.

Among the liabilities we looked at the equity, calculated by adding together share capital, share premium, reserves and yearly net income.

The economic values are related to the year's fundamental costs and revenues:

- The prices of guarantee services, which are the commissions collected for the service provided;

- The administrative expenses, including wages and salaries;

- The net income.

We calculated the cost to income ratio (CTI), determined by relating administrative expenses to the prices of 
the guarantee services. The ratio verifies the organisation's ability to cover costs with revenues and is an indicator of technical-managerial efficiency.

To test the hypothesis we used, in addition, the information supplied by the notes to the financial statements, which gave us both qualitative and quantitative data:

- The stock of guarantees granted, which indicates the real work of the confidi;

- The counter guarantees required by the consortium, which provide second degree hedging and reduce the risk of the activity performed;

- The stock of delinquency endured. This considers both losses on loans and non-performing assets and the impairments with some chance of recovery;

- The number of member enterprises, to check the appeal of the confidi;

- The number of employees, which enriches the detail of administrative expenses;

- The number of local units, in addition to the head office. Most guarantors operate on a local basis, with a single office. The presence of secondary units indicates more activity and, consequently, greater risks;

- The geographic area and the region of origin, which - completing the previous information - shows whether the confidi operates locally or in more than one region;

- The operational sector, portraying the organisation's diversification;

- The mergers completed, sometimes due to the desire to join the monitored group, other times to better cope with the difficulties of collecting receivables.

Finally, we evaluated the rating systems of the confidi. The situation is really heterogeneous. The organizations often assess the SMEs creditworthiness using a mix of qualitative and quantitative information, but they do not indicate the exact procedure in their balance sheets (accounting data). This prevents us from taking into account this variable. Anyway, we solved the problem considering the sample components in their unicity (firm-fixed effect model in the econometric analysis - see below).

In conclusion we used some macro magnitudes, to explain the confidi working system: the Italian reality.

In the analyzed period Italy is not outside the financial crisis. The Government debt is still increasing (the CAGR $_{2006-2015}$ is $+3.63 \%$ ), the GDP drops (-8.8\% is the evolution in time from 2006 to 2015), the investments go down, different businesses fail and the unemployment increases ( $+6.4 \%$ on annual basis). To describe this reality and its impact on the confidi we used the following macro variables, derived from Thomson Reuters Datastream, the Italian Statistics Department (Istat) and the official website of the Bank of Italy:

- The annual regional GDP, which incorporates rates of unemployment and inflation, indicating the economic trend from 2006 to 2015 ;

- The annual regional corporate mortality rate. The ratio can be an alternative to GDP, compared to which it shows an interesting added value, allowing the assessment of the risk of the confidi in consideration of the enterprises guaranteed;

- The annual credit disbursed at regional level. Funding follows the economic trend and supplies a valid portrayal of the role of confidi in support of SME;

- The return of Government Bonds $\left(\mathrm{r}_{\mathrm{GB}}\right)$, simulating the productivity of liquid resources that guarantors invest in government securities;

- The euribor, which represents the interest rate applied to the enterprises guaranteed.

\subsection{The Method}

All variables have been assessed and selected for analysis, which took place in two phases. First of all, the delinquency rate was calculated and explained, considering the characteristics of the sample (paragraph 4). Secondly, an econometric analysis was carried out, aimed at determining the variables on which the delinquencies discovered depend (paragraphs 5, 6 and 7). To offer a clearer picture, we have decided to illustrate the two methods separately, immediately followed by the results.

\section{The Delinquency Rate}

The delinquency rate is determined by relating the stock of impairments to the stock of guarantees. Overall, the 99 confidi reach an average ratio of $9 \%$, with a considerable increase between 2012 and 2013, where it rises from $10 \%$ to $16 \%$. Table 2 shows the details, indicating the annual rate and dividing the guarantors by 
geographic area, sector and regulations. In addition to the observation of the immediate values, the evolution in time is estimated by the CAGR between 2006 and 2015.

Table 2. The delinquency rate

\begin{tabular}{|c|c|c|c|c|c|}
\hline Year|Geographic area & Northwest & Northeast & Centre & \multicolumn{2}{|c|}{ South and Islands } \\
\hline 2006 & $1.17 \%$ & $2.01 \%$ & $4.77 \%$ & \multicolumn{2}{|l|}{$1.64 \%$} \\
\hline 2007 & $1.67 \%$ & $2.44 \%$ & $5.28 \%$ & \multicolumn{2}{|l|}{$1.10 \%$} \\
\hline 2008 & $1.98 \%$ & $3.46 \%$ & $6.32 \%$ & \multicolumn{2}{|l|}{$1.89 \%$} \\
\hline 2009 & $4.82 \%$ & $4.17 \%$ & $8.84 \%$ & \multicolumn{2}{|l|}{$6.36 \%$} \\
\hline 2010 & $5.86 \%$ & $3.25 \%$ & $8.43 \%$ & \multicolumn{2}{|l|}{$4.95 \%$} \\
\hline 2011 & $6.64 \%$ & $5.80 \%$ & $9.73 \%$ & \multicolumn{2}{|l|}{$7.17 \%$} \\
\hline 2012 & $6.40 \%$ & $5.07 \%$ & $15.02 \%$ & \multicolumn{2}{|l|}{$8.93 \%$} \\
\hline 2013 & $14.57 \%$ & $10.30 \%$ & $19.76 \%$ & \multicolumn{2}{|l|}{$9.90 \%$} \\
\hline 2014 & $19.62 \%$ & $10.77 \%$ & $15.04 \%$ & \multicolumn{2}{|l|}{$10.52 \%$} \\
\hline 2015 & $24.48 \%$ & $14.75 \%$ & $17.87 \%$ & \multicolumn{2}{|l|}{$13.93 \%$} \\
\hline CAGR 2006-2015 & $37.82 \%$ & $25.99 \%$ & $10.25 \%$ & \multicolumn{2}{|l|}{$46.10 \%$} \\
\hline YearlSector & AGR & CRF & TTS & IND & MS \\
\hline 2006 & $0.66 \%$ & $3.79 \%$ & $2.43 \%$ & $2.71 \%$ & $2.89 \%$ \\
\hline 2007 & $0.96 \%$ & $3.72 \%$ & $3.37 \%$ & $1.65 \%$ & $3.47 \%$ \\
\hline 2008 & $1.12 \%$ & $4.58 \%$ & $4.06 \%$ & $1.74 \%$ & $4.32 \%$ \\
\hline 2009 & $4.45 \%$ & $5.94 \%$ & $4.18 \%$ & $18.67 \%$ & $6.75 \%$ \\
\hline 2010 & $0.38 \%$ & $3.65 \%$ & $4.05 \%$ & $8.30 \%$ & $6.99 \%$ \\
\hline 2011 & $2.76 \%$ & $5.60 \%$ & $4.48 \%$ & $12.23 \%$ & $8.32 \%$ \\
\hline 2012 & $2.69 \%$ & $6.26 \%$ & $5.72 \%$ & $10.74 \%$ & $10.78 \%$ \\
\hline 2013 & $4.20 \%$ & $10.47 \%$ & $10.11 \%$ & $10.71 \%$ & $18.11 \%$ \\
\hline 2014 & $4.72 \%$ & $12.23 \%$ & $12.60 \%$ & $14.42 \%$ & $15.86 \%$ \\
\hline 2015 & $6.08 \%$ & $15.31 \%$ & $15.91 \%$ & $20.47 \%$ & $19.94 \%$ \\
\hline CAGR 2006-2015 & $46.29 \%$ & $22.16 \%$ & $23.33 \%$ & $22.58 \%$ & $21.02 \%$ \\
\hline YearlMonitoring & \multicolumn{2}{|c|}{ Monitored confidi } & \multicolumn{3}{|c|}{ Unmonitored confidi } \\
\hline 2006 & \multicolumn{2}{|l|}{$2.91 \%$} & \multicolumn{3}{|l|}{$2.84 \%$} \\
\hline 2007 & \multicolumn{2}{|l|}{$3.43 \%$} & \multicolumn{3}{|l|}{$3.35 \%$} \\
\hline 2008 & \multicolumn{2}{|l|}{$4.22 \%$} & \multicolumn{3}{|l|}{$4.32 \%$} \\
\hline 2009 & \multicolumn{2}{|l|}{$6.82 \%$} & \multicolumn{3}{|l|}{$6.23 \%$} \\
\hline 2010 & \multicolumn{2}{|l|}{$6.53 \%$} & \multicolumn{3}{|l|}{$4.95 \%$} \\
\hline 2011 & \multicolumn{2}{|l|}{$7.96 \%$} & \multicolumn{3}{|l|}{$5.88 \%$} \\
\hline 2012 & $10.24 \%$ & & $5.75 \%$ & & \\
\hline 2013 & $16.90 \%$ & & $8.97 \%$ & & \\
\hline 2014 & $15.17 \%$ & & $11.23 \%$ & & \\
\hline 2015 & $19.03 \%$ & & $14.53 \%$ & & \\
\hline CAGR 2006-2015 & $22.15 \%$ & & $18.19 \%$ & & \\
\hline Year $\backslash$ Mergers & Merged co & & Unmerg & & \\
\hline 2006 & $2.94 \%$ & & $2.69 \%$ & & \\
\hline 2007 & $3.45 \%$ & & $3.24 \%$ & & \\
\hline 2008 & $4.27 \%$ & & $4.05 \%$ & & \\
\hline 2009 & $6.67 \%$ & & $7.03 \%$ & & \\
\hline
\end{tabular}




\begin{tabular}{|c|c|c|c|c|c|}
\hline 2010 & $6.61 \%$ & & & & \\
\hline 2011 & $7.91 \%$ & & & & \\
\hline 2012 & $10.47 \%$ & & & & \\
\hline 2013 & $17.53 \%$ & & & & \\
\hline 2014 & $15.43 \%$ & & & & \\
\hline 2015 & $19.65 \%$ & & & & \\
\hline CAGR 2006-2015 & $21.09 \%$ & & & & \\
\hline YearlLocal units & $\mathbf{0}$ & 1 & 1 to 5 & 5 to 10 & $>10$ \\
\hline 2006 & $2.32 \%$ & $3.40 \%$ & $2.73 \%$ & $2.72 \%$ & $3.84 \%$ \\
\hline 2007 & $2.47 \%$ & $3.72 \%$ & $3.28 \%$ & $3.27 \%$ & $4.26 \%$ \\
\hline 2008 & $3.36 \%$ & $4.60 \%$ & $3.99 \%$ & $4.12 \%$ & $5.26 \%$ \\
\hline 2009 & $5.89 \%$ & $4.96 \%$ & $6.96 \%$ & $6.46 \%$ & $7.16 \%$ \\
\hline 2010 & $4.44 \%$ & $6.50 \%$ & $6.25 \%$ & $6.07 \%$ & $7.31 \%$ \\
\hline 2011 & $5.71 \%$ & $6.84 \%$ & $7.60 \%$ & $7.43 \%$ & $9.03 \%$ \\
\hline 2012 & $5.43 \%$ & $6.81 \%$ & $8.67 \%$ & $9.46 \%$ & $13.64 \%$ \\
\hline 2013 & $9.55 \%$ & $9.92 \%$ & $15.41 \%$ & $15.42 \%$ & $20.27 \%$ \\
\hline 2014 & $13.37 \%$ & $13.23 \%$ & $13.70 \%$ & $14.66 \%$ & $17.00 \%$ \\
\hline 2015 & $15.60 \%$ & $16.65 \%$ & $17.81 \%$ & $18.68 \%$ & $19.80 \%$ \\
\hline CAGR 2006-2015 & $21.66 \%$ & $32.59 \%$ & $22.79 \%$ & $22.78 \%$ & $15.91 \%$ \\
\hline
\end{tabular}

Detailed values also show a growth in delinquencies beginning in 2013, not offset by a sufficient increase in guarantees disbursed. The ratio is higher for confidi in the northwest, peaking in 2015 (25\%), at industrial level $(21 \%)$ and in the monitored group (19\%). This is justified by the fact that the highest percentage of subjects analysed comes from Northern Italy and industry is the sector worst hit by the crises, failing to benefit from sectoral diversification (Note 3). The fact that the highest value is recorded by the monitored confidi is a consequence of their size: a bigger consortium guarantees a higher number of enterprises and works in bigger territorial areas, exposing itself to a higher operating risk.

The situation changes slightly if we consider the average ratio for the whole decade. In this case, the guarantors of Central Italy take first place $(11 \%)$, while the industrial sector and the monitored group continue to prevail over the categories compared (10\% and $9 \%)$. This can be explained by observing another interesting ratio, the CAGR, which shows that the annual change over ten years is highest for confidi in the South and Islands (46\%). Consequently, as already indicated, guarantors in Central and Southern Italy are managed less attentively.

The table ends with details on the mergers and secondary offices available. It's no mere coincidence that the values are indicated after separation according to size. Many of the bigger confidi stem from extraordinary transactions, leading to the opening of new operational offices. The fact that the delinquency rate is higher for aggregated consortia ( $20 \%$ in 2015$)$ and for those with more than 10 operational offices might seem surprising ( $20 \%$ in 2013). In actual fact, the figures offer a good picture of the Italian situation. Many minor consortia have entered into extraordinary transactions to hedge the delinquencies endured. Those that have merged are not necessarily the best guarantors, but often those with greater operating difficulties. Similarly, the rate is higher for those with numerous local offices, because the increase in size and more extensive operation implicate endurance of a higher operational risk. The same information can be obtained from the ten-year average rate: $9 \%$ for aggregated confidi and $11 \%$ for those with more than 10 secondary offices.

The smaller confidi, which are not aggregated and have just one local unit, show the higher $\mathrm{CAGR}_{2006-2015}(24 \%$ and 33\% respectively), indicating a consistent increase in delinquencies endured. There are a couple of possible hypothesis: the first (more pessimistic) envisages their closure (unless the losses are recovered); the second (more optimistic) imagines saving them with new contributions from shareholders, with mergers or aggregations.

\section{Econometric Analysis: Model and Regressors}

The second part of the analysis was carried out using the econometric method, which was performed with careful 
selection of the variables downloaded, in order to avoid undesirable correlations. Being a panel, the model used was the fixed effects model, due to the unicity of the sample components.

The equation on which the regression was performed is expressed as follows:

$$
Y_{i t}=\beta_{0}+\beta_{1} X_{i t}+\beta_{2} Z_{i t}+\varepsilon_{i t}
$$

Where:

$\mathrm{Y}=$ delinquency rate, representing the dependent variable

$\mathrm{X}=$ vectors of the microeconomic independent variables

$\mathrm{Z}=$ vectors of the macroeconomic independent variables

$\varepsilon=$ terms of error

Subscript i represents the single confidi, subscript t the year.

The variables included in the regression are not always in absolute values, but sometimes in percentage terms or on a logarithm basis.

The analysis is carried out in two steps, described in sections 6 and 7: first on the total sample (99 confidi) and then on the monitored group only (33 units).

\section{Discussion 1: Regression on the Total Sample}

We began with the simplest regressions, subsequently integrated with the introduction of new variables.

The regression (1) tests the fundamentals of delinquencies: the cost to income ratio, the total assets and the regional GDP.

The figures show an importance of the first two variables, wich are both significant at $1 \%$ level. The coefficients are positive, which means that, in keeping with that disclosed in the description of the figures, the delinquency rate increases with the increase in the size and inefficiency of the confidi. The GDP shows a positive and significant relation with the delinquency rate. The result is justified by the fact that, during a declining phase, the guarantees granted diminish to the point where they cause a contraction in the delinquency rate. While the fundamentals provide a rational and sensible explanation for the insolvencies endured, the $\mathrm{R}^{2}$ says that the regressors explain just $38.5 \%$ of the dependent variable.

Then we moved on to the next analysis (2). In this case, the GDP was replaced first by the business mortality rate and then by regional credit. The latter was not explicative. If a confidi is affected by delinquency, the bank is less willing to grant credit to the companies it guarantees, in that the solvency (of both the company and the consortium) is severely compromised. So we looked at the mortality rate. As losses on receivables are recorded after bankruptcy, we tried to delay the ratio by a year. The result is more satisfactory than the GDP (1\% significance), showing that the deaths recorded in $\mathrm{T}_{0}$ influence the delinquencies of $\mathrm{T}_{1}$ (positive coefficient) and take $\mathrm{R}^{2}$ to $52 \%$. It should be noted that the total assets are no longer a relevant factor, in that, when the mortality rate is very high, delinquencies rise for all credit guarantee consortia, regardless of their size.

To test the phenomenon, we created a new regression (3), which replaces the total assets with the number of member enterprises. The result does not change: $\mathrm{R}^{2}$ remains at $52 \%$, while the only explicative variables are CTI and the business mortality rate.

Having found that the delinquencies of the confidi depend mainly on the economic trend and poor management, we furthered the study, calculating both ROE and ROA and placing them between the regressors. The results are not satisfactory, that is why we have focused the attention on the counter-guarantees, expressed in rate form, determined by relating the reassurances received on the guarantees disbursed (4). The counter-guarantees have a significance of $1 \%$ and confidence of $99 \%$. $\mathrm{R}^{2}$ rises to $54 \%$, indicating an improvement of the analysis performed. The fact that the coefficient is positive (the counter-guarantee increases delinquencies) comes as no surprise: the possibility to rely on an additional coverage encourages the consortium to adopt a riskier management policy. This means that, contrary to the way people think, the presence of counter-guarantees is not necessarily reassuring. The more prudent confidi doesn't require reassurance. The guarantor that resorts to this is less attentive to the activity performed.

For further examine the phenomenon, we added the available equity to the regressors, as this summarises the dimensions and internal resources useful to hedge the risk (5). The level of equity significance is $5 \%$ with a negative coefficient, while the $\mathrm{R}^{2}$ remains at $54 \%$. The information obtained is interesting, opposing that of the counter-guarantees. As the hedging resources are internal in this case, the more solid confidi risks less, because it 
tends to defend itself. Consequently, the managerial policy applied depends largely on the origin of the hedge funds. If these come from outside, the consortium is less prudent; if they originate internally, management is more selective and attentive.

Regressions (6) and (7) introduce two rates: that applied to the enterprises guaranteed and that earned by the confidi on the liquidity invested. Both variables are significant with a negative coefficient, which is easily justifiable. The higher the cost of the credit, the lower the requests for funding by SMEs. This results in a reduction in guarantees and delinquencies. The same goes for the $\mathrm{r}_{\mathrm{GB}}$, but reasoning in terms of return instead of cost. The higher the return on government bonds, the higher the country risk and that of the enterprises operating therein. Under these conditions, the consortium will prefer investing in securities rather than hedging situations hard to defend.

The last regression (8) adds little added value, but is shown to complete the figures: we added the variable relating to the number of employees. $\mathrm{R}^{2}$ does not improve $(56 \%)$, and the number of staff has absolutely no influence on the delinquency rate. The phenomenon is justified by the fact that the regressor, while not being related to delinquency, is included in administrative expenses (in CTI).

Table 3. Results 1

\begin{tabular}{|c|c|c|c|c|c|c|c|c|}
\hline Variable & $(1)$ & (2) & (3) & (4) & $(5)$ & (6) & (7) & (8) \\
\hline Const & $\begin{array}{l}-6.140 * * * \\
(2.014)\end{array}$ & $\begin{array}{l}-0.8005^{* *} \\
(0.3280)\end{array}$ & $\begin{array}{l}-0.5586^{* * *} \\
(0.1287)\end{array}$ & $\begin{array}{l}-0.4987 * * * \\
(0.08674)\end{array}$ & $\begin{array}{l}-0.01577 \\
(0.2578)\end{array}$ & $\begin{array}{l}0.3102 \\
(0.2771)\end{array}$ & $\begin{array}{l}0.4661 \\
(0.2840)\end{array}$ & $\begin{array}{l}0.4686 \\
(0.2851)\end{array}$ \\
\hline CTI & $\begin{array}{l}0.004427 * * * \\
(0.001427)\end{array}$ & $\begin{array}{l}0.002827 * * \\
(0.001319)\end{array}$ & $\begin{array}{l}0.002804 * * \\
(0.001322)\end{array}$ & $\begin{array}{l}0.003050^{* *} \\
(0.001324)\end{array}$ & $\begin{array}{l}0.003049 * * \\
(0.001326)\end{array}$ & $\begin{array}{l}0.002895^{* *} \\
(0.001315)\end{array}$ & $\begin{array}{l}0.002800^{* *} \\
(0.001310)\end{array}$ & $\begin{array}{l}0.002801 * * \\
(0.001314)\end{array}$ \\
\hline GDP & $\begin{array}{l}0.4258^{* *} \\
(0.1817)\end{array}$ & & & & & & & \\
\hline Assets & $\begin{array}{l}0.08253 * * * \\
(0.01871)\end{array}$ & $\begin{array}{l}0.01689 \\
(0.02122)\end{array}$ & & & & & & \\
\hline Mortality-rate $_{t}$ & & $\begin{array}{l}-1.302^{* * *} \\
(0.2929)\end{array}$ & $\begin{array}{l}-1.239 * * * \\
(0.3108)\end{array}$ & $\begin{array}{l}-1.143 * * * \\
(0.3267)\end{array}$ & $\begin{array}{l}-1.131 * * * \\
(0.3290)\end{array}$ & $\begin{array}{l}-1.075 * * * \\
(0.3266)\end{array}$ & $\begin{array}{l}-0.7855^{* *} \\
(0.3483)\end{array}$ & $\begin{array}{l}-0.7828^{* *} \\
(0.3499)\end{array}$ \\
\hline Mortality-rate $_{t-1}$ & & $\begin{array}{l}9.474 * * * \\
(1.002)\end{array}$ & $\begin{array}{l}9.464 * * * \\
(0.9551)\end{array}$ & $\begin{array}{l}8.739 * * * \\
(1.056)\end{array}$ & $\begin{array}{l}9.240 * * * \\
(1.084)\end{array}$ & $\begin{array}{l}7.404 * * * \\
(1.233)\end{array}$ & $\begin{array}{l}5.799 * * * \\
(1.410)\end{array}$ & $\begin{array}{l}5.764 * * * \\
(1.438)\end{array}$ \\
\hline SMEs & & & $\begin{array}{l}0.003564 \\
(0.01381)\end{array}$ & & & & & \\
\hline Counter-guarantees & & & & $\begin{array}{l}0.1114 * * * \\
(0.02422)\end{array}$ & $\begin{array}{l}0.1063^{* * *} \\
(0.02445)\end{array}$ & $\begin{array}{l}0.1014 * * * \\
(0.02429)\end{array}$ & $\begin{array}{l}0.09625^{* * *} \\
(0.02428)\end{array}$ & $\begin{array}{l}0.09618^{* * *} \\
(0.02435)\end{array}$ \\
\hline Equity & & & & & $\begin{array}{l}-0.03280^{* *} \\
(0.01566)\end{array}$ & $\begin{array}{l}-0.04371 * * * \\
(0.01593)\end{array}$ & $\begin{array}{l}-0.04496 * * * \\
(0.01586)\end{array}$ & $\begin{array}{l}-0.04511^{* * *} \\
(0.01592)\end{array}$ \\
\hline Euribor & & & & & & $\begin{array}{l}-1.137 * * * \\
(0.3743)\end{array}$ & $\begin{array}{l}-0.9399 * * \\
(0.3822)\end{array}$ & $\begin{array}{l}-0.9238^{* *} \\
(0.3961)\end{array}$ \\
\hline $\mathrm{r}_{\mathrm{GB}}$ & & & & & & & $\begin{array}{l}-1.074 * * \\
(0.4645)\end{array}$ & $\begin{array}{l}-1.074 * * \\
(0.4674)\end{array}$ \\
\hline Employees & & & & & & & & $\begin{array}{l}0.0001730 \\
(0.0008005)\end{array}$ \\
\hline $\mathrm{R}^{2}$ & 0.384766 & 0.518553 & 0.519362 & 0.538032 & 0.543705 & 0.552741 & 0.557920 & 0.557553 \\
\hline
\end{tabular}

Standard errors in brackets: * indicates 10 percent significance; $* *$ indicates 5 percent significance; $* * *$ indicates 1 percent significance

\section{Discussion 2: Regression on Monitored Confidi}

The results obtained from the regression analysis are shown in Table 4 and, once again, they highlight the importance of the quality of the management of confidi, this being one of the main drivers of the delinquency rate. Considering its significance and the form used to calculate this ratio two elements seem to emerge with greater force from the results disclosed. First of all, the positive coefficient indicates, as expected, that management's ability to efficiently manage resources, summarised in the capacity to contain the costs of the structure and in the reaching of a revenue balance, is one of the most important elements when it comes to determining the health of confidi. It is also presumable that a better management capacity will also affect the capacity to keep costs down, as well as the methods and procedures used to analyse and manage the credit risk. 
Secondly, the implementation of appropriate systems for pricing the guarantees provided could be an important element. In particular, pricing which adequately considers the risk of the individual applicant enterprises and opportunely differentiates the relative costs of the guarantees can allow a more attentive consideration of the creditworthiness of each enterprise, providing additional resources from firms characterised by a higher risk, in order to destine them to further provisions to hedge any future losses.

Contrarily to what we assumed, the dimensional aspect does not present the sign expected. In particular, using the total assets as proxy of the dimensions of confidi, it is interesting to note the positive relationship between the above mentioned variable and the delinquency rate. These are extremely interesting results, as they seem to refute the assumption according to which bigger organisations are able to gain benefits from the greater possibilities of diversification, limiting the guarantees portfolio risk. Contrarily, the results obtained show how an increase in the dimension generally corresponds to a higher delinquency rate. The evidence described partly contrasts with the logic of the new regulations, which have raised the volume of minimum financial assets necessary to operate as supervised confidi, highlighting that the loss of contact with the home territory and the slackening of the close links with associated enterprises can reduce the informative advantage deriving from the direct knowledge of the guaranteed firms. This is a particularly important element, as it could nullify the mechanism of peer monitoring typical of mutualistic guarantee institutions, making the operations of these structures increasingly similar to those of banks, in which the role of soft information takes on marginal importance.

Also of particular interest are the results obtained by analysing the part of the guarantees portfolio hedged by counter-guarantees. Excluding regression [5], which particularly tested the impact of this variable with the equity, in all the other specifications a positive and statistically significant relationship emerges between the intensity of the use of counter-guarantees and the delinquency rate. The results obtained suggest that the use of funds destined to transfer a fraction of risk could, in actual fact, trigger a moral hazard mechanism which would, in turn, generate a de-responsibility of the confidi involved. According to Beck et al. (2010), our results also seem to indicate a lack of efficiency in the use of counter-guarantee instruments as forms of public support for the system of SMEs, because, while facilitating access to credit, they would end up encouraging confidi to issue more guarantees, potentially also to enterprises that are not completely worthy. In this sense, it is necessary to emphasise the fact that the method of operation of the Medio Credito Centrale Fund could also have a considerable impact on the above relationship. This Fund allows banks to guarantee good quality loans, eliminating the relative capital requirements. As the Fund provides collateral only to transactions with a lower credit risk, this could cause a shift of the risk, encouraging banks to redirect only those enterprises characterised by higher risk towards the mutualistic guarantee institutions, triggering a consistent increase in the risk of their portfolios. This would mean that the reference market would be characterised by enterprises with a higher average risk than those counter-guaranteed at central level. That mentioned earlier with regard to the possibility that confidi with more resources of their own are more efficient in terms of the capacity to reduce the weight of their delinquencies is confirmed when the equity of each confidi is included in the analyses. The results highlight the fact that the confidi with less equity are characterised by a higher delinquency rate. Contrarily, those characterised by a higher amount of equity are more efficient in the management of their resources, suggesting that this can effectively be a key variable in determining the state of health of the confidi. The relationship which emerges remains substantially unchanged, even when a term of interaction between the amount of equity and the counter-guarantee rate is introduced. While the coefficient of the latter is not significant, the inclusion of the above interaction highlights that the lower risk of the confidi characterised by high equity is substantially reduced in the case of intense use of counter-guarantee instruments. This has an important practical implication in relation to the methods used by public institutions to support the mutualistic guarantee institution system. The disbursement of resources aimed at strengthening the equity of the confidi seems to be preferable to the assignment of funds destined solely to the transferral of risk.

To take into account the economic context which involves the entrepreneurial fabric in which the confidi operate and offer their guarantees, a series of macroeconomic variables have been introduced into the analysis, just like in the previous paragraph. Once again, as could easily be imagined, the relationship between the confidi delinquency rate and the GDP of the region where they are located is positive. It is inevitable that part of the delinquency rate is explained by the economic situation of the territory of origin, where the enterprises that benefit from the guarantees are located. Should these be hit by the economic crisis, it is obvious that greater difficulties in repaying the loans taken out would emerge. Examining the mortality rate of the firms on a regional basis, in order to take into consideration also an average measure of risk on the market to which confidi refer, once again a positive relationship emerges between the its value delayed by a period and the delinquency rate. 
This confirms the initial theory according to which a regional market characterised by a higher probability of default by associated firms has a significant impact on the risk to which the confidi operating in it are exposed, regardless of their capacity to adequately manage the risk. The existence of a relationship which is positive only in terms of the delay mortality rate is entirely normal, considering that the figures used are annual and the bureaucratic procedure for the transferral of transactions to delinquency could make them open to disclosure in the financial statements only from the following year. Lastly, it is interesting to note that, for the sample consisting exclusively of supervised confidi, the impact of this variable on the delinquency rate is much lower than that obtained on the whole sample. This dynamic would seem to indicate that other variables could have a significant impact on the delinquency rate of the supervised confidi, which could be capable of more adequately grasping the creditworthiness of the affiliated enterprises. Contrarily, the impact of the trend in interest rates is more pronounced for the subsample of supervised confidi. The cost of credit for enterprises is a variable of fundamental importance in determining their delinquency rate.

Table 4. Results 2

\begin{tabular}{|c|c|c|c|c|c|}
\hline Variable & (1) & (2) & (3) & (4) & (5) \\
\hline \multirow[t]{2}{*}{ Const } & $-5.866 * *$ & $-1.267 * *$ & $0.4790^{* *}$ & -0.01711 & $0.6021 * *$ \\
\hline & $(1.879)$ & $(0.2869)$ & $(0.2199)$ & $(0.4655)$ & $(0.2268)$ \\
\hline \multirow[t]{2}{*}{ CTI } & $0.04149 * *$ & $0.03727 * *$ & $0.03311^{* *}$ & $0.03256^{* *}$ & $0.03599 * *$ \\
\hline & $(0.008787)$ & $(0.008946)$ & $(0.009060)$ & $(0.009084)$ & $(0.009105)$ \\
\hline \multirow[t]{2}{*}{ Assets } & $0.06661 * *$ & $0.05954 * *$ & & 0.02967 & \\
\hline & $(0.01452)$ & $(0.01780)$ & & $(0.02484)$ & \\
\hline \multirow[t]{2}{*}{ Counter-guarantees } & $0.1949 * *$ & $0.1480^{* *}$ & $0.1292 * *$ & $0.1312 * *$ & -0.5212 \\
\hline & $(0.02035)$ & $(0.02258)$ & $(0.02232)$ & $(0.02242)$ & $(0.3272)$ \\
\hline \multirow[t]{2}{*}{ Equity } & & & $-0.04002 * *$ & $-0.04068 * *$ & $-0.04809 * *$ \\
\hline & & & $(0.01157)$ & $(0.01179)$ & $(0.01218)$ \\
\hline \multirow[t]{2}{*}{ Contr*Eq } & & & & & $0.03888 * *$ \\
\hline & & & & & $(0.01952)$ \\
\hline \multirow[t]{2}{*}{ GDP } & $0.4100^{* *}$ & & & & \\
\hline & $(0.1716)$ & & & & \\
\hline \multirow[t]{2}{*}{ Mortality-rate $_{\mathrm{t}}$} & & $-0.8797 * *$ & $-0.7948 * *$ & $-0.7725^{* *}$ & $-0.7747 * *$ \\
\hline & & $(0.2955)$ & $(0.2895)$ & $(0.2905)$ & $(0.2874)$ \\
\hline \multirow[t]{2}{*}{ Mortality-rate $_{t-1}$} & & $4.169^{* *}$ & $4.141^{* *}$ & $3.872^{* *}$ & $4.248^{* *}$ \\
\hline & & $(1.116)$ & $(1.137)$ & $(1.160)$ & $(1.129)$ \\
\hline \multirow[t]{2}{*}{ Euribor } & & & $-1.559 * *$ & $-1.202 * *$ & $-1.530 * *$ \\
\hline & & & $(0.3428)$ & $(0.4550)$ & $(0.3405)$ \\
\hline $\mathrm{R}^{2}$ & 0.6541 & 0.6933 & 0.7222 & 0.6799 & 0.7279 \\
\hline
\end{tabular}

\section{Conclusions: Benefits, Limits and Suggestions}

This work highlights some of the determinants of the confidi delinquency rate, considering jointly both the individual features of the confidi and several macroeconomic variables, introduced to take into account the context related to the market in which every confidi operates. With reference to the former, management's capacity to efficiently manage the resources available is a relevant element in determining the state of health of the confidi. A good management, able to contain costs and maximising revenues deriving from supply of guarantees makes it possible to pay more attention to delinquencies, presumably because those who diversify the costs of guarantees in relation to the risk of the enterprises, in order to obtain greater resources from less deserving firms, could succeed in gaining a better assessment of the real creditworthiness. We have also found that larger confidi, while allowing greater diversification of the portfolio, can actually lead to a loss of a whole series of soft information, fundamental for an adequate assessment of the applicant enterprises. Despite the use of counter-guarantees provided in favour of the confidi having been theoretically helpful to facilitate access to 
credit by SMEs, the results obtained highlight the fact that the transferral of the risk using these instruments could lead to an accentuation of the moral hazard, inducing the confidi to provide guarantees also to firms not fully deserving. On the contrary, the use of instruments in support of the system aimed at incrementing the resources of the confidi, equipping them with more equity, seems to be preferable, as it is the subjects with less equity that reveal a higher delinquency rate. The macroeconomic control variables on the other hand indicate quite uniformly that the confidi delinquency rate is inevitably linked to the economic trend of the respective territory of origin: a higher delinquency rate can be found during recessions, with a general reduction in GDP being associated to a high rate of enterprise mortality.

In conclusion, the results permit to understand which elements jeopardize the survival of confidi. This is useful for the associated SMEs, for the lending banks and for the Italian legislator. Practical and social implications are therefore connected. A better and good management will help both the associated SMEs to obtain debt capital (that, otherwise, would be denied or more expensive) and the banks in protecting themselves against bad and doubtful credits. In the same time, the forecasting of the riskier confidi will help the policy maker in the individuation and in the use of correct instruments of rescue. We cannot forget that the failure of the confidi (and that of the supported SMEs) leads to another important problem: the unemployment. The evidence is furthermore useful both for Bank of Italy and for the Organism of control of not monitored confidi.

On the contrary, the principal limitation of the work is that it is referred to the Italian market. The second one depends on the fact that in Italy there are associations which do not indicate their delinquencies in the balance sheet. This problem does not depend on the authors, but it precludes the possibility of a more comprehensive analysis. Nevertheless, we can interpret these limitations as added-value. First of all, the difficulties in collecting credits are an import problem in Italy and their study could be a reference for other country systems. Secondly, in 2016 some changes have been introduced in the confidi accountings standards. Probably this would create better conditions for new research in the future.

\section{Acknowledgments}

Although the paper is the result of an equal joint effort by the two authors, their primary individual contributions are reflected in the following sections of the paper: Alessio Bongiovanni sections 1, 2, 7, 8 and Cristina Rovera $3,4,5,6$.

\section{References}

Bartoli, F., Ferri, G., Murro, P., \& Rotondi, Z. (2012). Bank-firm relations and the role of mutual guarantee institutions at the peak of the crisis. Journal of Financial Stability, 9, 90-104. https://doi.org/10.1016/j.jfs.2012.03.003

Beck, T., Klapper, L. F., \& Mendoza, J. C. (2010). The typology of partial credit guarantee funds around the world. Journal of Financial Stability, 6, 10-25. https://doi.org/10.1016/j.jfs.2008.12.003

Busetta, G., \& Zazzaro, A. (2012). Mutual loan-guarantee societies in monopolistic credit markets with adverse selection. Journal of Financial Stability, 8, 15-24. https://doi.org/10.1016/j.jfs.2011.02.004

Columba, F., Gambacorta, L., \& Mistrulli, P. E. (2009). The effect of mutual guarantee consortia on the quality of bank lending. Munich Personal Repec ARichive.

Columba, F., Gambacorta, L., \& Mistrulli, P. E. (2010). Mutual guarantee institutions and small business finance. Journal of Financial Stability, 6, 45-54. https://doi.org/10.1016/j.jfs.2009.12.002

Gai, L., \& Ielasi, F. (2016), Operational drivers affecting credit risk of mutual guarantee institutions. The Journal of Risk Finance, 15, 275-293. https://doi.org/10.1108/JRF-12-2013-0087

Gai, L., Ielasi, F., \& Rossi, F. (2013). Mutual guaranteed loans: the determinants of defaults. Proceedings Cambridge Business and Economics Conference, July, Cambridge.

Isaia, E., Pia, P., Damilano, M., De Vincentiis, P., \& Rovera, C. (2015). I Confidi in Italia 2015, Torino, Camera di Commercio Industria Artigianato e Agricoltura di Torino.

Mistrulli, P. E., \& Vacca, V. (2011). I confidi e il credito alle piccole imprese durante la crisi. Questioni di Economia e Finanza della Banca d'Italia, 105, October.

Stiglitz, J. E. (1990). Peer monitoring and credit markets. World Bank Economic Review, 4, 351-366. https://doi.org/10.1108/JRF-12-2013-0087 


\section{Notes}

Note 1. See Statistics of Bank of Italy.

Note 2. 2016 balance sheets are not usable, because the Italian confidi are assuming a different operative structure, due to a change in the legislative regulation in the accountings standards. It is therefore impossible a comparison between past and new balance sheets.

Note 3. The Istat $\mathrm{CAGR}_{2006-2015}$ of the industrial production ratio is $-2.52 \%$.

\section{Copyrights}

Copyright for this article is retained by the author(s), with first publication rights granted to the journal.

This is an open-access article distributed under the terms and conditions of the Creative Commons Attribution license (http://creativecommons.org/licenses/by/4.0/). 